\title{
Heat Transfer Characteristics in a Heat Pipe Using Water-Hydrocarbon Mixture as a Working Fluid. (An Experimental Study)
}

\author{
Dr. Hussain H. Ahmad \\ Mech. Eng. Dept. / College of Engineering/Mosul University
}

\begin{abstract}
The heat pipe is a very effective device in heat transport, therefore it is used in many industrial applications especially in cooling systems. In the present experimental work, wickless heat pipe(thermosyphon)is designed and constructed from a copper tube of inside and outside diameters $(13.5)$ and $(15.5) \mathrm{mm}$ respectively with total length of (600)mm divided into three sections evaporator; adiabatic section and a finned air cooled condenser simulating the actual applications in practice of this device. Pure water, pure hydrocarbon fluid (acetone) and mixtures of the two fluids at different ratios by weight were used as working fluid to investigate the effect of a working fluid type and mixture ratio on the performance of the device. Results show that using pure fluid is more effective than using mixture. Comparison between results of the present work and a theoretical correlation shows a good agreement especially when using pure fluid.
\end{abstract}

Keywords: Thermo syphon; Heat pipe; Mixture.

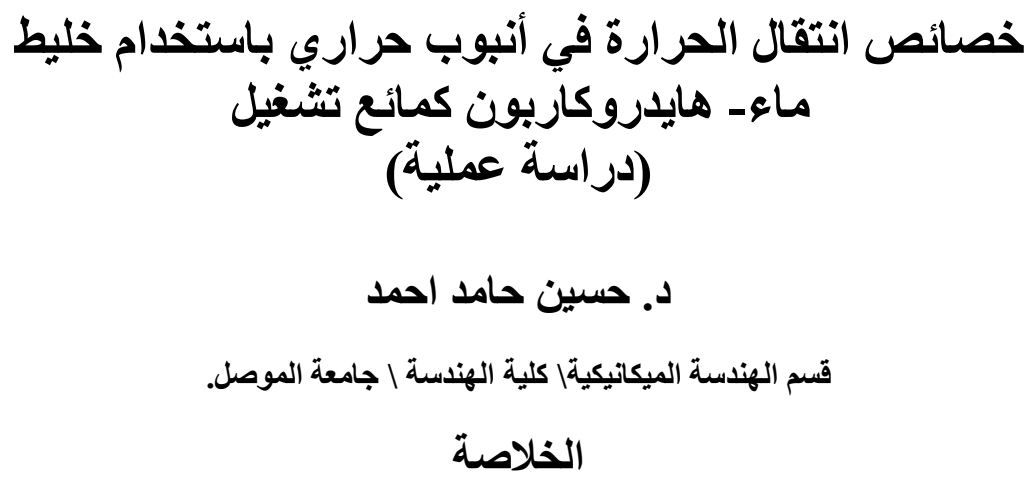

الأنبوب الحراري جهاز ذو فعالية عالية في نقل الحرارة. لذا يستخدم في كثير من التطبيقات الصناعية وخاصة

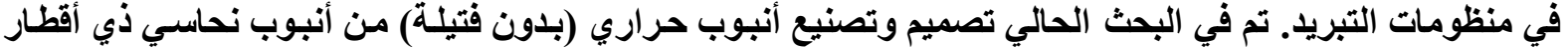

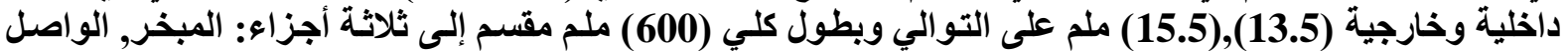

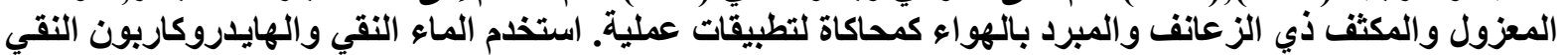

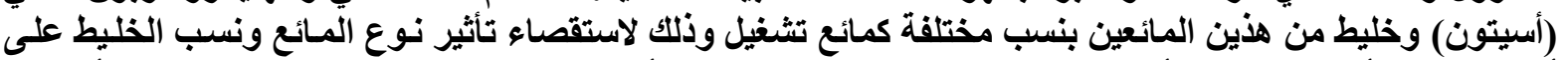

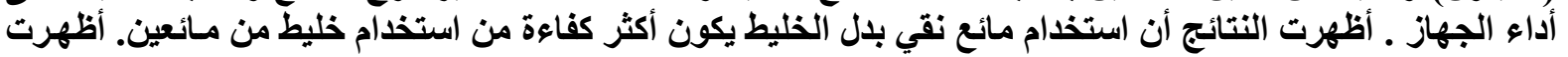

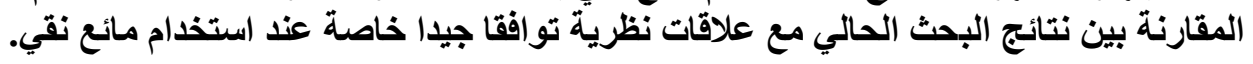




\section{Nomenclature}

\begin{tabular}{|c|c|c|c|c|c|}
\hline Sym & Meaning & Unit & Sym & Meaning & Unit \\
\hline A & Area & $\mathrm{m}^{2}$ & $\overline{\mathrm{P}_{\mathrm{sat}}}$ & Vapor Saturated & $\mathrm{Pa}$ \\
\hline $\mathrm{B}_{\mathrm{o}}$ & Bond number & --- & $\mathrm{P}_{\mathrm{V}}$ & Vapor Pressure & $\mathrm{Pa}$ \\
\hline $\mathrm{C}$ & Constant used in Eq.3 & --- & $\mathrm{P}_{\mathrm{r}}$ & Prandtl number & ---- \\
\hline $\mathrm{C}_{\mathrm{p}}$ & Specific heat capacity & $\mathrm{J} / \mathrm{kg} .{ }^{\circ} \mathrm{C}$ & $q$ & Heat flux & $\mathrm{W} / \mathrm{m}^{2}$ \\
\hline $\mathrm{f}_{1}, \mathrm{f}_{2}, \mathrm{f}_{3}$ & Factor used in Eq.1 & $\mathrm{J} / \mathrm{kg} .{ }^{\circ} \mathrm{C}$ & $\mathrm{Q}_{\text {in }}$ & Input power & $\mathrm{W}$ \\
\hline $\mathrm{G}$ & Gravitation acceleration & $\mathrm{m} / \mathrm{s}^{2}$ & $\mathrm{Q}_{\max }$ & maximum heat flux & $\mathrm{W} / \mathrm{m}^{2}$ \\
\hline $\mathrm{h}$ & heat transfer coefficient & $\mathrm{W} / \mathrm{m}^{2} .^{\circ}$ & $\mathrm{T}_{\mathrm{e}}$ & evaporator outside & ${ }^{\circ} \mathrm{C}$ \\
\hline $\mathrm{h}_{\exp }$ & $\begin{array}{l}\text { Experimental heat transfer } \\
\text { coefficient }\end{array}$ & $\begin{array}{l}\mathrm{W} / \mathrm{m}^{2} \cdot{ }^{\circ} \\
\mathrm{C}\end{array}$ & $\mathrm{T}_{\mathrm{ad}}$ & adiabatic temperature & ${ }^{\circ} \mathrm{C}$ \\
\hline $\mathrm{h}_{\mathrm{fg}}$ & Latent heat of vaporization & $\mathrm{J} / \mathrm{kg}$ & $\mathrm{T}_{\mathrm{s}}$ & Saturation temperature & ${ }^{\circ} \mathrm{C}$ \\
\hline ID & Inside Diameter & $\mathrm{m}$ & $\rho_{1}$ & Liquid density & $\mathrm{kg}$ \\
\hline $\mathrm{k}$ & Thermal conductivity & $\mathrm{W} / \mathrm{m} .{ }^{\circ} \mathrm{C}$ & $\rho_{\mathrm{v}}$ & Vapor density & $\mathrm{kg}$ \\
\hline $\mathrm{k}_{\mathrm{p}}$ & Factor used in eq.1 & --- & $1 \mu$ & Liquid viscosity & $\mathrm{kg}$ \\
\hline $\mathrm{L}$ & Evaporator length & $\mathrm{m}$ & ${ }_{v} \mu$ & Vapor viscosity & $\mathrm{kg} / \mathrm{m}$. \\
\hline OD & Outside diameter & $\mathrm{m}$ & $\sigma$ & Surface tension & $\mathrm{N} / \mathrm{m}$ \\
\hline $\mathrm{p}_{\text {atm }}$ & atmospheric Pressure & $\mathrm{Pa}$ & $v$ & kinematics viscosity & $\mathrm{m}^{2} / \mathrm{s}$ \\
\hline
\end{tabular}

\section{1-Introduction}

Due to advancing technology in electronic equipment and other applications such as air space crafts, air conditioning and refrigeration systems where heat dissipation is very important, the use of heat pipe is very effective. The heat pipe is very superior in heat transport from the source to the sink[1,2]. The conventional heat pipe is a closed end tube with a wick lining on its inside surface or without wick in case of wickless heat pipe (thermosyphon). The heat pipe is charged with a certain amount of a working fluid. It is divided into three sections; the evaporator where heat is supplied to the device from a heat source, adiabatic section and a condenser where heat is dissipated to heat sink. The heat pipe operating principles are based on evaporation of working fluid where heat is carried by vapors to the condenser and rejected out due to condensation. The condensate fluid returns back to the evaporator due to the wick structure or by gravity. The amount of heat that can be transported through the use of latent heat is several order of magnitude greater than transported by sensible heat for a geometrically equivalent system [3]. Considerable number of experimental and theoretical works have been carried out on the design and application of heat pipe concerning the performance and the important affecting parameters such as, material, diameter, working fluid ,filling ratio, range of temperature ,critical heat flux and orientation. Ngugen-chi etal [4] investigated experimentally the performance of a vertical two-phase close thermosyphon (wick less heat pipe) with water as a working fluid. They studied the maximum performance of the device. Nutaphan etal[5] carried out a set of experimental tests to investigate the critical heat flux due to flooding limit of wickless heat 
pipe (theromsyphon) using mixturs of working fluid. They concluded that the use of mixture of working fluid such as trithylene glycol-water mixture can extend the heat transport limitation compared with pure water. Bezrodly and Alekseenko [6] in their study, recommended the liquid fill should be at least $(50 \%)$ of the evaporator volume to avoid the dry out condition. Akachi etal [7]reached almost the same conclusion. Noi[8]investigated the effect of three parameters :input heat transfer rates, the working fluid filling ratios and the evaporator lengths (aspect ratio) on a two-phase closed thermosyphon performance. He concluded that the optimum filling ratio at which the thermosyphon operates at its best for a certain aspect ratio. Jouhara and Robinson[9]carried out an experimental investigation of the performance of thermosyphon charged with water and dielectric heat transfer liquids. Generally, they found that the water charged thermosyphon was outperformed the other working fluids in both the effective thermal resistance as well as maximum heat transport capabilities. Almost all available experimental researches in studying the heat pipe performance adapted water cooled condenser and in general they used pure fluids as a working fluid.

In practical applications, the heat pipe condenser is cooled by natural or forced convection. For this reason in the present work, the forced convection is used to cool the finned tube condenser and mixture of water hydrocarbon fluid (acetone) is used as a working fluid. Pure water and pure acetone were also used separately as a working fluid for comparison. The heat pipe used is a copper tube with inside diameter (13.5) $\mathrm{mm}$, the outside diameter (15.5) $\mathrm{mm}$ and the total length is (600) $\mathrm{mm}$. Finally, comparison between the present work results and a theoretical correlation is made.

\section{2- Operating limits}

There are three limits which can reduce the performance of the heat pipe (thermosyphon). These limits are:

2.1-Flooding limit: this phenomenon occurs at high operating temperature [4]and when the working fluid charge is higher than $(50 \%)$ of the evaporator volume. Critical heat flux of this phenomenon can be calculated according to the following equation proposed by ESDU[10] :

$$
\begin{aligned}
& Q_{\text {max. }}=f_{1} f_{2} f_{3} \lambda A_{c s}\left[g \sigma\left(\rho_{\ell}-\rho_{v}\right)\right]^{0.25} \cdot \rho_{v}{ }^{0.5} \\
& f_{1}=0.0331 B_{o}^{2}+0.8161 B_{o}+302134 \\
& \mathrm{~B}_{0}=\text { Bond number=ID }\left(\frac{g\left(\rho_{\ell}-\rho_{v}\right)^{0.5}}{\sigma}\right) \\
& \mathrm{f}_{2}=\mathrm{k}_{\mathrm{p}}{ }^{-0.17} \quad \text { if } \quad \mathrm{k}_{\mathrm{p}} \leq 40000 \\
& \boldsymbol{k}_{p}=\frac{\boldsymbol{P}_{v}}{\left[g \sigma\left(\rho_{\ell}-\rho_{v}\right)\right]^{0.5}} \\
& \mathrm{f}_{2}=0.615 \quad \text { if } \quad \mathrm{k}_{\mathrm{p}}>40000 \\
& \mathrm{f}_{3}=1 \quad \text { if the pipe is vertical }
\end{aligned}
$$




\section{2-Dry out:}

This limit occurs when the working fluid charge is very small . The Critical heat flux can be predicted by the following expression[2]:

$Q_{\max .}=0.012 h_{f g} \rho_{v}\left[\frac{\rho_{l}-\rho_{v}}{\rho_{v}}\right]^{0.6}$

This phenomenon can be avoided when the working fluid charge is large. So in this work the dry-out is unexpected since the fluid charge is $(90 \%)$ of the evaporator volume.

\section{3-Boiling limit:}

This limit occurs when there is a large working fluid charge and high radial heat flux generating a blanket of bubbles coating the inside tube surface which reduces dramatically the heat transfer rate and finally reduces the heat pipe performance[2].

Flooding and boiling limits were avoided by using low heat fluxes. All the experimental results showed that the two limits have not been reached.

\section{3-Experimental Setup:}

\subsection{Heat pipe Test Section}

The heat pipe is constructed from a copper tube with inside and outside diameters of (13.5) and (15.5) $\mathrm{mm}$ respectively. The total length of the heat pipe is (600) $\mathrm{mm}$, divided into three sections; evaporator (200) $\mathrm{mm}$, adiabatic section (100) $\mathrm{mm}$ and finned condenser (300) $\mathrm{mm}$. The evaporator and adiabatic sections are insulted by (50) $\mathrm{mm}$ thick asbestos layers. Eleven calibrated(copper-constantan) thermocouples were inserted into the outside surface of the heat pipe along its total length to measure the temperature. The evaporator is heated by an electrical coil wrapped around its outside surface. The power input is varied and measured by variac and a wattmeter. A fan is used to cool the condenser with air velocity of $(0.225$ to 0.25$) \mathrm{m} / \mathrm{s}$ measured by an air velocity meter (Model WILD MTR28). Insulation temperature and ambient temperature were measured by using Two calibrated thermocouples as shown in figure (1). Pure water, pure acetone and filling mixture ratios (30\%, 50\%, 70\% and 85\%) acetone/mixture by weight were investigated. Input power ranged from (125) W to (250)W with an interval of (25)W. Heat losses from the evaporator and adiabatic section was calculated from insulation outside surface temperature and ambient temperature.

In general heat losses did not exceed $(10 \%)$ of the input power.

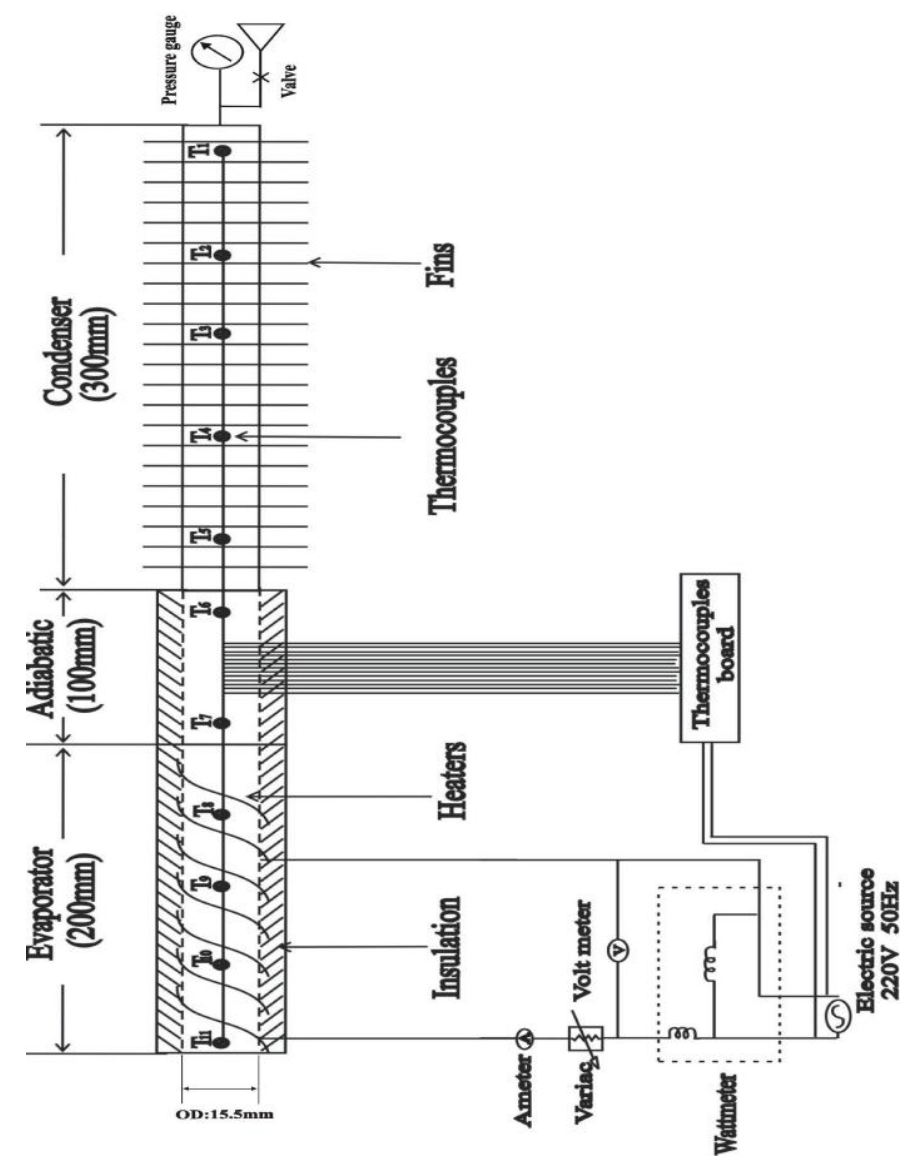

Figure (1) experimental set-up 
In this work the investigation is concentrated on the heat transfer rate in the evaporator section and the heat transfer coefficient is calculated by the following equation [9]:

$$
h_{\text {exp. }}=\frac{Q_{\text {in }}}{\pi \times O D \times L \times\left(T_{e}-T_{a d}\right)}
$$

\section{4-Results and Discussion}

\section{1- Effect of power Input and Filling Ratio:}

Pure water, pure acetone and mixture of water and acetone tests were carried out at different power inputs ranging from (125) to (250) $\mathrm{W}$ with an interval of $(25) \mathrm{W}$. Figures (2-7) show the variation of temperature along the heat pipe at the above conditions. Figure (2) shows the temperature distribution with distance for pure water from the bottom end of heat pipe. The temperature starts increasing gradually to reach a maximum value at the middle of the evaporator, and then it begins to decrease through the rest part of the evaporator and adiabatic section. The temperature decreases sharply at the condenser section and remains almost constant along it. The temperature profile is the

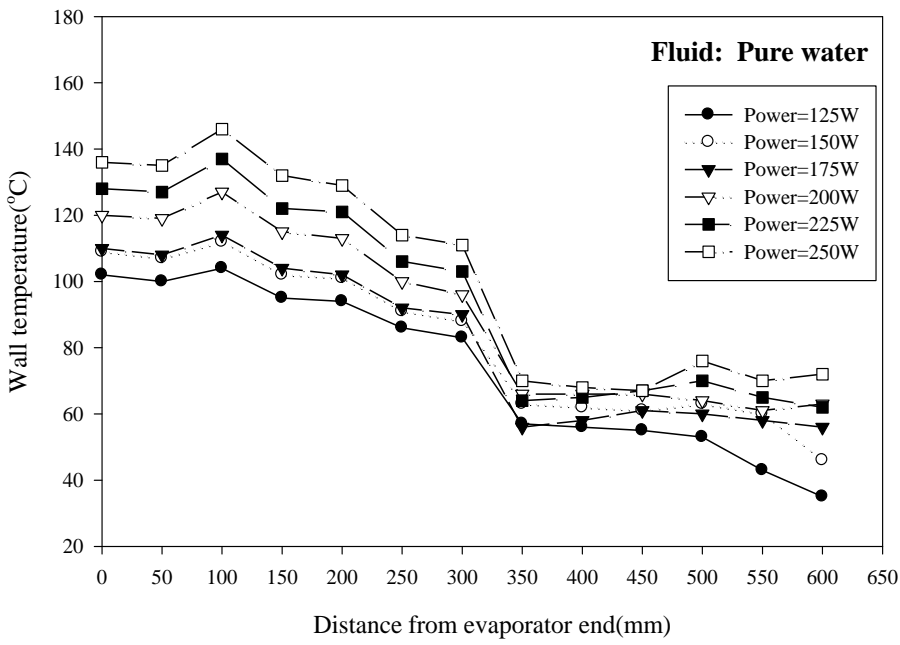

figure(2): variation of HP wall temperature vs distance at different power inputs for pure water. same for all power inputs but values of temperature increase as the power inputs increase. The maximum temperature at the middle of evaporator is $(150)^{\circ} \mathrm{C}$ when the power input is $(250)^{\circ} \mathrm{C}$. The minimum temperature is $(105){ }^{\circ} \mathrm{C}$ at the same point when the power input is $(125){ }^{\circ} \mathrm{C}$.

Figure (3) shows the profile of temperature throughout the heat pipe when the fluid mixture ratio is $(30 \%)$. As it is noticed from the figure, the temperature profiles are identical for all power inputs especially across the evaporator and adiabatic section with maximum temperature $(105){ }^{\circ} \mathrm{C}$ when the power input is (250) $\mathrm{W}$ and minimum temperature $(120){ }^{\circ} \mathrm{C}$ at power input (125) W.

For fluid mixture ratio (50\%), Figure(4), the temperature distribution along the evaporator is different from the previous cases and it can be

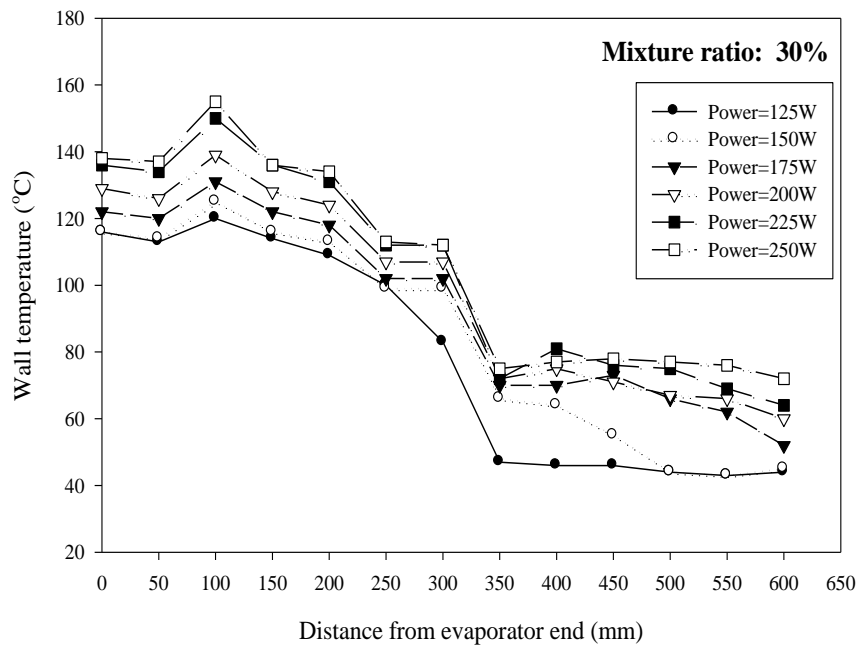

Figure(3): Varaition of HP wall temperature vs distance at different power inputs for mixture ratio $30 \%$. 
described as follows; the maximum temperature is at the end of the evaporator, not at the middle as seen before. The other thing noticed is that the temperature decreases gradually at power inputs (250 and 225)W. There is no clear reason for this behavior but it can be attributed to the very complex mechanism of the heat transfer when a mixture is used as a working fluid. This mechanism of heat transfer includes:

- Two phase -two fluid heat transfer.

- Evaporation and condensation of two different fluids with different

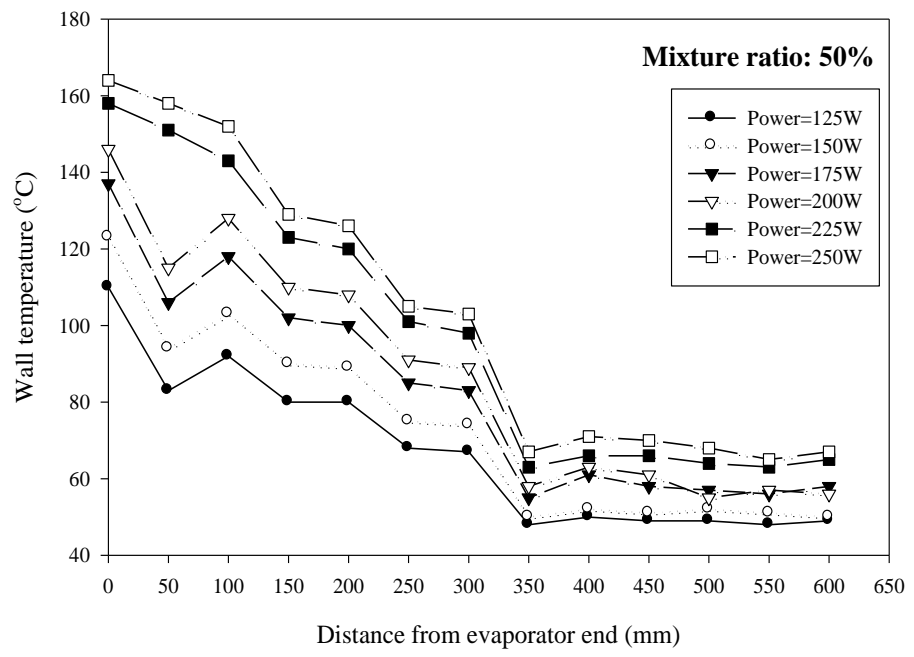

Figure(4):Varaition of HP wall temperature vs distance at different power inputs for mixture ratio $50 \%$. properties especially the boiling point and the latent heat of evaporation.

- Counter flow of two phase vapor and two phase condensate liquid.

All above mechanisms make it difficult to explain clearly what is going on inside the heat pipe. But the temperature oscillation can be attributed to the increasing level of the liquid pool in the evaporator temporally by the returning condensate flow from the condenser till a certain level is reached, then the vapor moves upward carrying with it liquid from the bottom of the evaporator to the condenser until it forms a plug there. When the weight of the plug becomes high enough it returns back to the evaporator again. This phenomenon causes variation of the temperature even during the thermosyphon steady state operation [4].

In general, the behavior shown in figure (4) can be seen in figure (5) where the fluid mixture ratio is $(70 \%)$. As the acetone increases in the mixture $(85 \%)$, the maximum temperature becomes clearly at the middle of the evaporator for all heat inputs and the profile of the temperature is almost identical, figure (6). The temperature at each point decreases in a uniform way as it is seen from the figure.

For pure acetone as a working fluid, figure(7), the profile of temperature distribution is almost identical to that of pure water

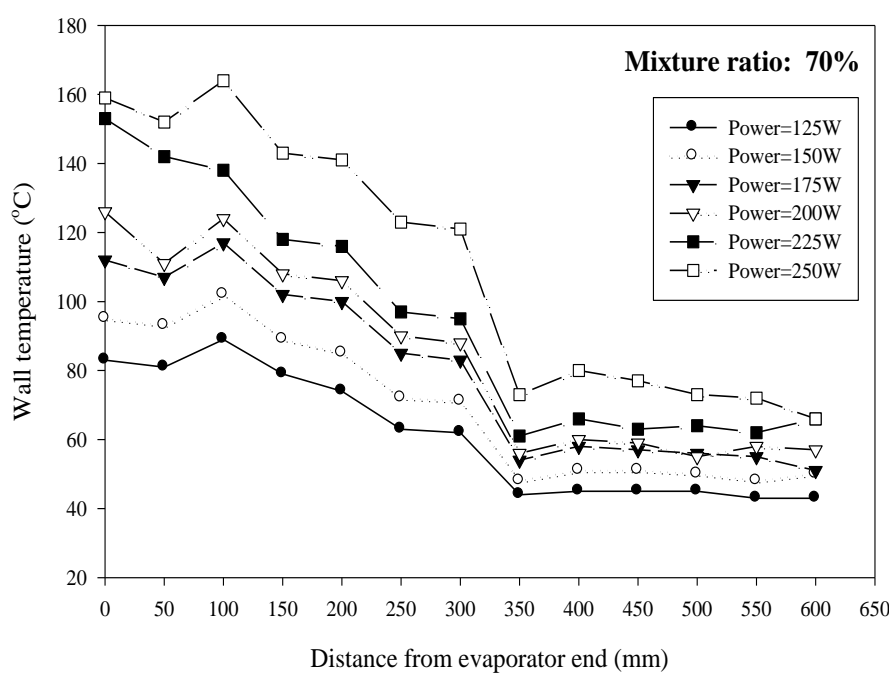

Figure(5): Varaition of HP wall temperature vs distance at different power inputs for mixture ratio $70 \%$. especially at the high power input but with lower values at low power input (125)W. 


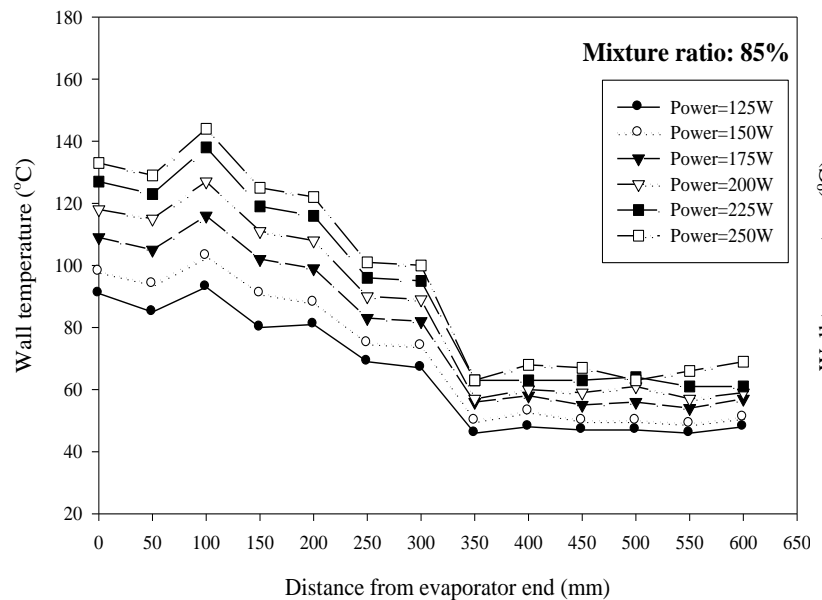

Figure(6): Varaition of HP wall temperature vs distance at different power inputs for mixture ratio $85 \%$.

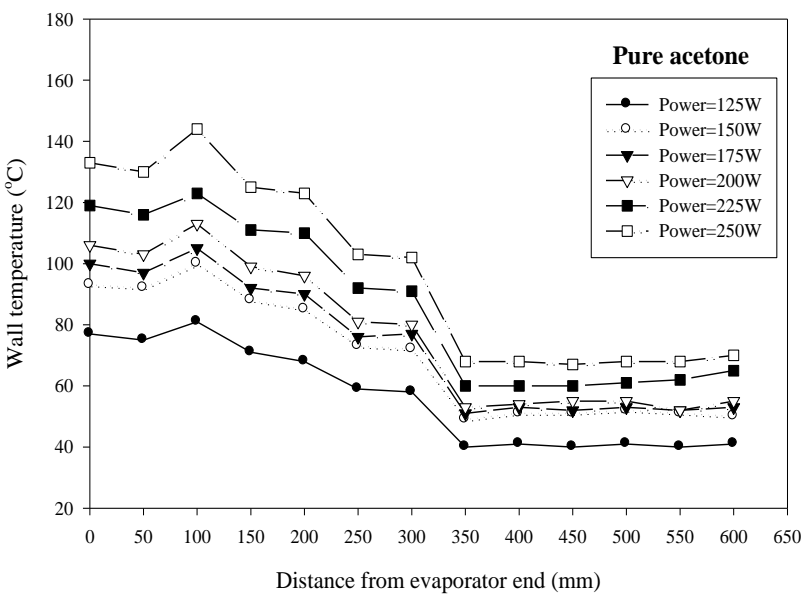

Figure(7): variation of HP wall temperature vs distance at different power inputs and pure acetone.

Figures (8 and 9) show the variation of heat transfer coefficient of the evaporator with respect to the mean evaporator temperature at different ratios of working fluid mixtures. Figure (8a) shows the heat transfer coefficient of the evaporator for pure water.
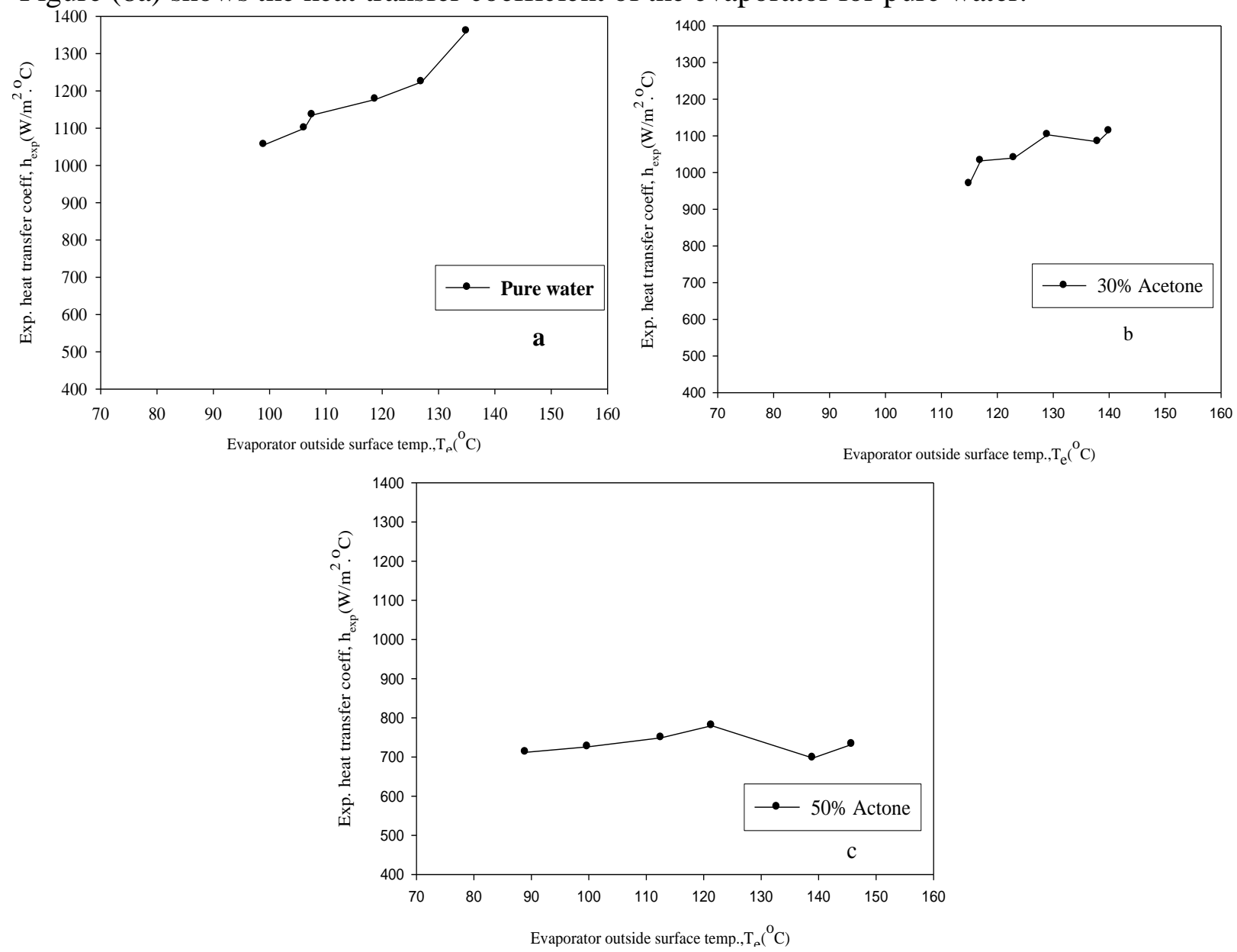

Figure (8):heat transfer coefficient. vs. evaporator outside surface temperature for:
a- Pure water
b- $30 \%$ acetone.
c- $50 \%$ acetone. 
It is clear from the figure that the heat transfer coefficient increases as the temperature increases due to the increase of the power input and the decrease in temperature difference between the evaporator and the adiabatic section. The maximum heat transfer coefficient obtained is (1380) W/m. ${ }^{\circ} \mathrm{C}$ when the power input is (250) W. The addition of acetone to water decreases the value of heat transfer coefficient as it is noticed when the mixture ratio is $(30 \%)$, figure (8b). When the mixture consists of two equal volumes of acetone and water $(50 \%)$, the heat transfer coefficient becomes lower, ranging between $(700) \operatorname{to}(750) \mathrm{W} / \mathrm{m}^{2} .{ }^{\circ} \mathrm{C}$ as shown in figure $(8 \mathrm{c})$.

In figure(9a)when the mixture ratio becomes (70\%)the heat transfer coefficient increases gradually as the temperature of the evaporator increases to reach a value of about $(1100) \mathrm{W} / \mathrm{m}^{2} .{ }^{\circ} \mathrm{C}$. This can be applied to the case when the mixture ratio is $(85 \%)$, figure $(9 \mathrm{~b})$. For pure acetone $(100 \%)$, the value of the heat transfer coefficient is $(980) \mathrm{W} / \mathrm{m}^{2}{ }^{\circ}{ }^{\circ} \mathrm{C}$. When the temperature ranging between $(73)$ and $(92)^{\circ} \mathrm{C}$ and starts to increase until it becomes $(1100) \mathrm{W} / \mathrm{m}^{2}{ }^{\circ} \mathrm{C}$ and stays almost constant inspite of the evaporator temperature increase, figure $(9 \mathrm{c})$.

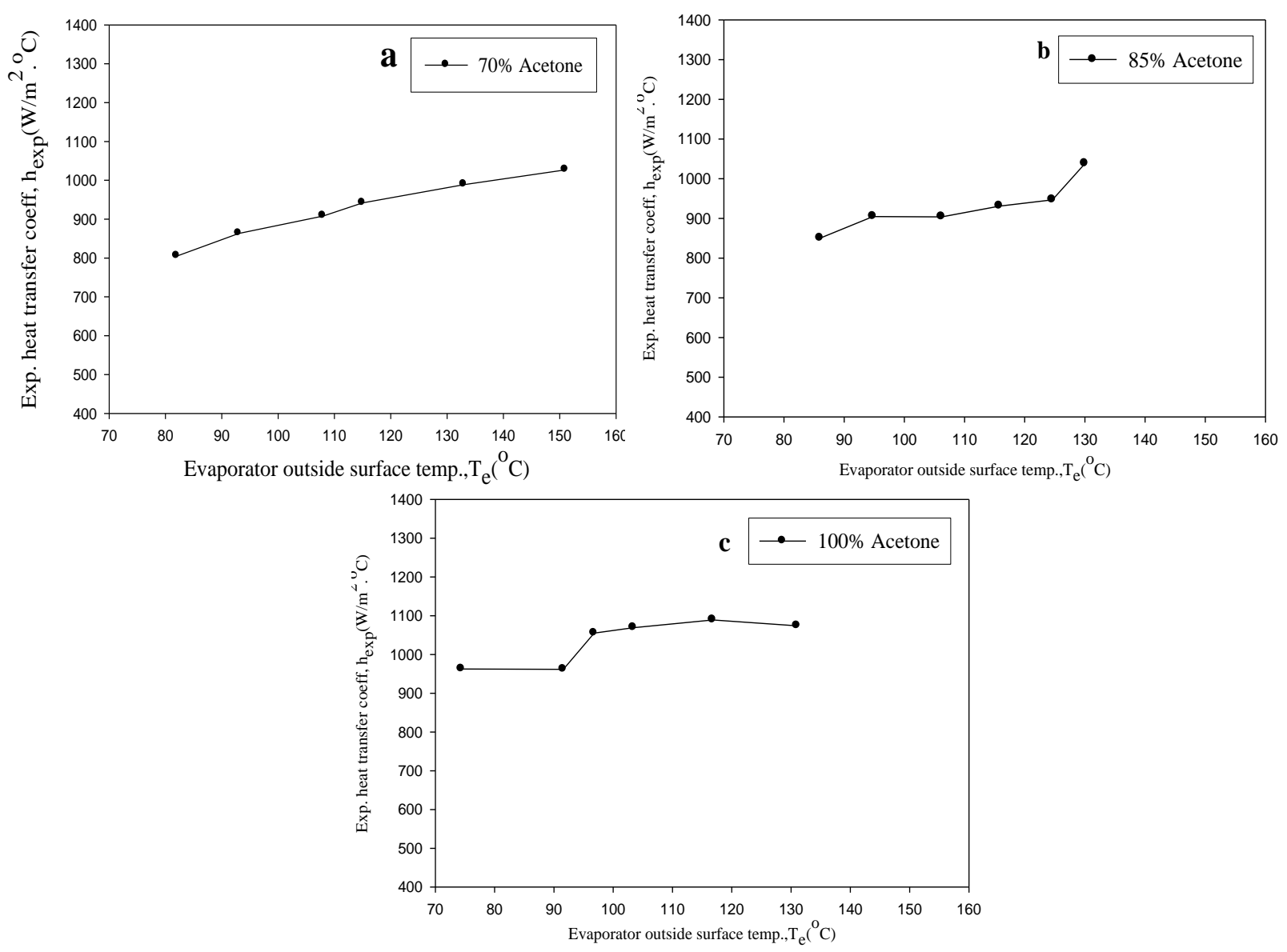

Figure(9):Heat transfer coefficient vs. evaporator outside surface temperature for: a- Acetone $70 \%$. b- Acetone $85 \%$. c- Pure acetone. 


\section{5-Comparision Between the Present Work Results and a Theatrical Correlation.}

Fig. (10) shows the comparison between the heat transfer coefficients of the present work results and that obtained by using Labuntsov correlation $[11,12]$ for pure water and pure acetone at different power inputs.

Labuntsov correlation is:

$$
h_{L a b .}=C\left[1+10\left(\frac{\rho_{v}}{\rho_{\ell}-\rho_{v}}\right)^{2 / 3}\right]\left(\frac{k^{2}}{v \sigma\left(T_{s}+273.15\right)}\right)^{1 / 3} \times q^{2 / 3}
$$

From Eq. 3:

$$
h_{\text {exp. }}=\frac{Q_{i n}}{\pi \times O D \times L \times\left(T_{e}-T_{a d}\right)}
$$

By taking $\mathrm{C}=0.04$ for water and 0.06 for acetone instead of $\mathrm{C}=0.075$ assumed by Labuntsov, good agreement is achieved for both fluids(water and acetone) especially at low input powers but the disagreement increases as the power input increases. The deviation is due to that this correlation is based on data that covers nucleate pool boiling performed on a horizontal, thick metal plate of copper while this work is performed on a thermosyphon.

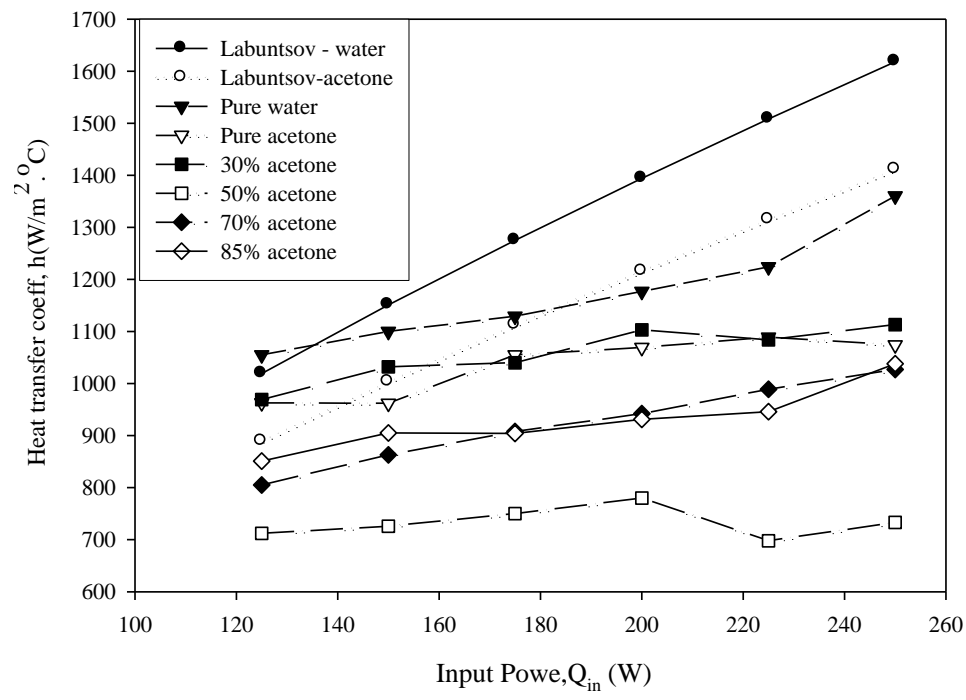

Figure(10):Comparison of heat transfer coefficient the present experiment and theoretical correlation results at different power inputs for different mixture ratio of

\section{6- Conclusions:} fluids.

- Generally the temperature of the evaporator outside surface increases from the bottom and reaches a maximum value at almost the middle of the evaporator and starts to decease through the rest part of the evaporator and adiabatic section.

- Oscillation of the temperature along the evaporator is mainly due to the complex mechanism of the evaporation and condensation of working fluid in addition to the counter flow of vapor and condensate liquid.

- The maximum heat transfer coefficient is obtained when water is used as a working fluid and lower heat transfer coefficient is obtained when a mixture is used as a working fluid with a ratio of $50 \%$.

- The temperature along the condenser is almost steady and isothermal. 


\section{References:}

1-Reay, D.A., "Advances in Heat Pipe Technology", proceeding of the IV $^{\text {th }}$, International Heat Pipe Conference, September, London, UK, 1981.

2- Reay, D.A. and Kew, P.A., "Heat Pipe" fifth ed., Butterwort-Heinemann, Oxford, 2006.

3-Ochterbeck, J.M., "Heat Pipe", Heat Transfer Handbook, Hoboken, NJ: John Wiley\& Sonse, Inc, 2003.

4-Nguyen, - Chi, Groll, M., Dang-Van, Th., "Experimental Investigation of Closed TwoPhase Thermosyphon", AIAA, $14^{\text {th }}$ Thermophysics Conference, Orlando, Florida, June 4-6, 1979, pp.239-246.

5-Nataphan, A., Tiansuwan, J. and Kiatsiriroat, T., "Enhancement in Heat Transport in Thermosyphon Air Preheater at High Temperature with Binary Working Fluid", A Case Study of TEG-Water", Applied Thermal Engineering 22, (2002), pp.251-266.

6-Bezrodny, M.K., and Alekseenko, D.B., "Investigation of Critical Region of Heat and Mass Transfer in Low Temperature Wickless Heat Pipes", High Temperature, Vol. 15, pp.309313, 1977.

7-Akachi, H., Polasek, F. and Sutlc, P., "Pulsating Heat Pipe" Proceeding of $5^{\text {th }}$ International Heat Pipe Symposium, Melbourn, Australia, 1996, pp.208-217.

8-Noie, S.H., "Heat Transfer Characteristics of a Two-Phase Closed Thermosyphon", Applied Thermal Engineering 25, 2005, pp.495-506.

9-Jouhara, H., and Robenson, A.J., “ Experimental Investigation of a Small Diameter TwoPhase Closed Thermosyphon Charged Water, FC-84, FC-77, FC-3283”, Applied Thermal Engineering 30, 2010, p201-21.

10- Engineering Data Science Unit No. 81038, "Heat Pipe Performance of Two-Phase Closed Thermosyphons",ESDU,International Publishing,London,UK, 1983.

11-Labuntsov,"Heat Transfer Problems with Nucleate Boiling of liquids", Thermal Engineering 19(a), 1972, 21-28.

12-Pioro, I.L., Rohsenow, W. and Doerffer, S.S., “Nucleate Pool-Boiling Heat Transfer”, II: Assessment of Prediction Methods, International Journal of Heat and Mass Transfer 47, 2004, pp.5045-5057.

13- Heat Exchanger design Handbook, Hemisphere Publishing Corporation, New York, 1983.

14- Pioro, I.L., "Experimental Evaluation of Constants for the Rohsenow Pool BoilingCorrelation”, Int. Journal of Heat and Mass Transfer 42, 1999, pp.2003-2013. 